\title{
Left-peripheral expansion of the English NP${ }^{1}$
}

\author{
FREEK VAN DE VELDE \\ Research Foundation Flanders (FWO) /University of Leuven
}

(Received 30 April 2010; revised 24 November 2010)

This article is concerned with peripheral modifiers in the English noun phrase. It is argued that this kind of modification is an Early Modern English innovation. Later, in the nineteenth century, the slot underwent a rapid extension on both the type and the token levels, as is shown by historical corpus inquiry. To account for the diachronic processes involved, a constructional, usage-based approach is used, with an onomasiological rather than a semasiological perspective on grammaticalisation.

\section{Introduction}

This article inquires into the diachrony of 'peripheral modifiers' in the noun phrase (NP) ${ }^{2}$ such as focus particles and other adverbials which occupy the far left edge, preceding even the determiners (see Payne \& Huddleston 2002: 436-9). An example is given in (1):

\section{(1) even the government (BNC)}

I will argue that the peripheral modification slot is the place where interpersonal, subjective modification of the NP is preferably managed. The slot, which is filled by adverbs that normally operate high up in the syntactic tree, is an innovation in Early Modern English, and has been growing steadily over the past centuries. The notion of growth is understood here (i) as a rise in token frequency, in other words the frequency of this optional slot being lexically instantiated in the NP, (ii) as a proliferation of the different lexemes that are allowed in this construction, and (iii) as an increase in the phonetic, morphological and syntactic complexity of the slot fillers. As to (iii), I will show that the slot started out as a position in the NP hosting (short) focus particles, but over the centuries came to accommodate more complex adverbials, adverbial PPs and even clause fragments. The whole 'growth' process is a result of a series of reanalyses and analogical extensions.

In order to support these claims, this study draws on historical corpus data, extracted from the following corpora: ${ }^{3}$

\footnotetext{
${ }^{1}$ I would like to thank Clair Hill, the attendants of the NP1 workshop in Vigo and the anonymous reviewers for helpful comments on earlier drafts of this article. Remaining errors are obviously solely the responsibility of the author.

2 I will not assume the DP hypothesis of Abney (1987), but instead adopt the traditional structure of the NP as in (2), following Quirk et al. (1985) and Payne \& Huddleston (2002).

${ }^{3}$ I am well aware of the drawbacks of some of these corpora, such as the $O E D$ quotation database (but see Mair 2004: 123-5 for a defence of the practice followed in this article).
} 
- BNC: Davies, Mark. 2004-. BYU-BNC: The British National Corpus. Available online at http://corpus.byu.edu/bnc;

- CB: COBUILD Corpus: Collins Wordbanks Online Service. See www.collins.co.uk/cobuild/;

- CEMET: Corpus of Early Modern English Texts (De Smet);

- CLMETEV: Corpus of Late Modern English (De Smet 2005);

- GoEx: The internet as a text corpus, queried with the aid of the search engine Google;

- OED: Oxford English Dictionary. See www.oed.com.

The article is structured as follows. First, in section 2, the organisation of the English NP is discussed, and the way in which the peripheral modifiers fit in this syntactic structure. Section 3 goes into more detail about the syntax and semantics of the peripheral modifiers. In sections 4, 5 and 6 the diachronic data are presented. Section 7 explores the consequences for theories of language change, and section 8 rounds off with the conclusions.

\section{Basic slots in the English NP}

The structure of the (English) noun phrase (NP) is a matter of ongoing debate. Various theoretical approaches each come with their own template. Some are relatively parsimonious, such as Huddleston's (1988: 85); others, such as Tucker's (1998) or Scott's (2002), have numerous slots or projections accommodating all sorts of nominal features, both lexical and functional.

Conflicting as the different models may seem, there are several points that all sides agree on. One common idea is that the determiner is at the left edge of the (English) noun phrase, either as a specifier or a head of a projection high up the syntactic tree, or as the outer dependent of the noun. Ignoring theory-specific details about hierarchic structure, this yields the following representation:

(2) $\left[\mathrm{NP} \quad \begin{array}{l}\mathrm{D} \\ \text { the }\end{array} \quad\left[\cdots, \begin{array}{l}[\mathrm{N}]]] \\ \text { man }\end{array}\right.\right.$

It is not difficult, however, to find apparent exceptions. In English, basic determiners such as articles may be preceded by elements like all and both, which, on the basis of the mutual exclusivity of most determiners with the articles (see Pullum \& Huddleston 2002: 539 and Dryer 2007: 161), should be denied determiner status. This said, there is a way out. Elements like all and both are aptly called 'predeterminers' (see Payne \& Huddleston 2002: 433-6). In that way, they are subsumed under the determiner, which is now seen as a complex. ${ }^{4}$ The predeterminer is then an extension

${ }^{4}$ In some accounts, the determiner complex also hosts postdeterminers (see Quirk et al. 1985: 261; Halliday 1994: 183; Biber et al. 1999: 258-9; Breban 2010), although there is no agreement on what lexemes fill this postdeterminer slot. For Quirk et al. (1985) it is the slot where quantifiers and numerals are situated, whereas for Sinclair et al. (1990: 70) or Breban (2010), it is the slot for adjectives like other, same, usual - and some have argued that it is not a separate position in the NP tree (see Payne \& Huddleston 2002; Van de Velde 2009a). 
of the determiner. Indeed, there is a close connection between determiners and predeterminers: syntactically all and both can be used alternatively as predeterminers and as determiners, as illustrated in (3)-(6), and semantically, all and both are quantifiers that operate in the realm of determination (see Davidse 2004 for the theoretical underpinnings of this idea). ${ }^{5}$

(3) Predeterminer:

In Switzerland, all the men carry halberds. (BNC)

(4) Predeterminer:

Both the men in expensive suits meet me on big-suited territory. (BNC)

(5) Determiner:

All men check their tyres at least once a month. (BNC)

(6) Determiner:

Both men were taken to hospital. (BNC)

Ignoring the postmodifiers, we arrive at the representation in (7), a structure that recognises that determination - whether realised by the determiner alone or by a combination of a predeterminer (abbreviated as Q, for quantifier) and a determiner forms the top level of the syntactic NP tree. ${ }^{6}$ This structure features in one form or another in various reference grammars (e.g. Quirk et al. 1985: 1340; Givón 1993: 248; Biber et al. 1999: 240-1; Brinton 2000: 170).

$\left.\begin{array}{rlllll}\text { (7) }[\mathrm{NP} & \mathrm{Q} & {[\mathrm{D}} & {[} & & [\mathrm{N}]]\end{array}\right]$

What this structure does not account for, however, is a range of other elements that also can precede regular determiners. In contrast with the predeterminers they are neither syntactically nor semantically akin to determiners. Examples are given in (8)-(9).

(8) Only a fool would risk doing so. (BNC)

(9) resulting in possibly a damaging loading on the switching device and overheating with loss of efficiency. (BNC)

These elements seem to call for an additional slot for noun phrase modification, or another projection above the determiner. In Payne \& Huddleston's outline of the NP, they go under the name of peripheral modifiers (see Payne \& Huddleston 2002: 436-9), and constitute a separate slot. This yields an NP template as in (10), where Pm stands for peripheral modifier.

\footnotetext{
5 Predeterminer use of both does not seem to be very common in English, though. Note also that there is a third construction, in which the determiner is used as a head with a postmodifier introduced by of (both/all of the men, BNC).

6 The template in (7) does not do full justice to the idea that the predeterminer and the determiner form a constituent together. A slightly more complex representation such as [NP [Q D] [ . [ [N]]] may be more appropriate. As this does not immediately affect the analysis of the peripheral modifier, which is at issue in the present article, I will stick to the simpler representation in (7).
} 


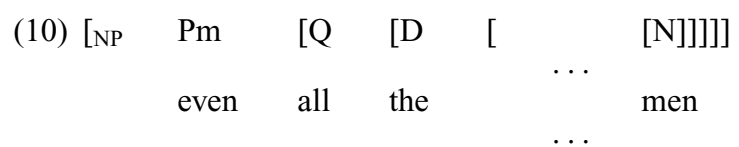

3 Semantics and syntax of peripheral modifiers

Before turning to diachronic data, let's first have a look at what elements can function as peripheral NP modifiers. Payne \& Huddleston (2002: 436-9) list the following elements for English:

(11) Focusing modifiers (e.g. only the corner of the painting)

(12) Scaling modifiers ${ }^{7}$ (e.g. almost the same conclusion)

(13) Frequency modifiers (e.g. invariably the most unconvincing explanations)

(14) Domain modifiers (e.g. architecturally the most impressive building)

(15) Modal modifiers (e.g. possibly the worst performance of his career)

(16) Evaluative modifiers (e.g. unfortunately very limited qualifications)

(17) Quantifying modifiers in predicatives (e.g. She is every inch a philosopher)

(18) Reflexives (e.g. The manager herself had approved the proposal)

Apart from the reflexive pronoun in $(18),{ }^{8}$ the list is fairly consistent: peripheral modifiers are adverbs (or XPs functioning as adverbials, like the NP every inch in (17) or the PP to all intents and purposes in (19). See also section 6, below, for more complex XPs).

(19) Mafia or the Cosa Nostra is the largest criminal organization in the south of Italy with to all intents and purposes a global influence. (GoEx)

Peripheral modifiers are adverbs or PPs, but the reverse does not hold: not all adverbs or PPs can function as peripheral modifiers. ${ }^{9}$

(20) *yesterday the other man

(21) * locally the presence

What decides an adverb's potential to function as a peripheral modifier in the NP? With the exception of frequency adverbs, the peripheral premodifiers in (11)-(17) all belong to the subjunct and disjunct category, rather than to the adjunct category, to use the terminology of Quirk et al. (1985: 475-653). As such, they belong to the 'interpersonal' domain, which includes everything that pertains to the interaction between speaker and

${ }^{7}$ Scaling modifiers are often seen as a subset of the focusing modifiers. In this article, the two classes will be conflated.

8 The syntax of the reflexive is notably complex, and (18) is probably of a somewhat different nature than the other peripheral modifiers. For one thing, it cannot normally precede the determiner, which seems to be the preferred position for ordinary peripheral modifiers.

9 The adverbs in (20)-(21) can be used as a postmodifier of the noun as in the newspaper yesterday or the presence locally. This is, however, a different construction than the one in (11)-(17) (see Payne et al. 2010 for an analysis). 
hearer, such as appraisal, epistemic stance and discourse organisation. ${ }^{10}$ Interpersonal modifiers typically have scope over other modifiers and over negation, as is reflected in their high position in syntactic trees, their preference for left position, and their non-truth-conditionality. This concurs with the observation that peripheral modifiers occupy the leftmost position in the NP. As noted by Quirk et al. (1985: 1341), the order of the premodifiers in the English NP follows a subjective-to-objective order from left to right, and if we take up the suggestion of Davidse et al. (2008) that determiners are also subjective in nature, the subjective-to-objective order goes beyond the adjectival string.

The interpersonal nature of peripheral modifiers is evident in the case of modal and evaluative modifiers, as in (15) and (16). Focusing modifiers also clearly have interpersonal import, as they deal with speakers' stance or expectation (see e.g. Nevalainen 1991: 76-83; Barbiers 1995: 47, 49, 60; Traugott 2006: 343; Harbert 2007: 32). The same is true for some, though admittedly not all, scaling modifiers. As regards domain adverbs, see (14) and (22), their status is not an easy matter (see Ramat \& Ricca 1998: 191-3), but they too are probably rather high up in the syntactic tree, and may consequently be considered to belong to the interpersonal domain. Note that domain adverbs are not easily brought under the scope of the negation or substituted by a pro-form (see (23) and (24), respectively), which are syntactic tests for (interpersonal) subjectivity (see e.g. De Smet \& Verstraete 2006).

(22) Politically this was informed by the demands coming from women's organizations. (BNC)

(23) *Not politically this was informed by the demands coming from women's organizations.

(24) ${ }^{*} \mathrm{So} /{ }^{*}$ in such way this was informed by the demands coming from women's organizations? (Politically)

The peripheral NP modifiers often go overlooked in reference grammars. ${ }^{11}$ This may be partly due to their elusive syntax. Focusing modifiers (also called focus particles), the most prominent type of peripheral modifiers, can occur with all sorts of phrases (see Pullum \& Huddleston 2002: 586-7) and need not be adjacent to their semantic argument (see (25)). If discontinuity is a criterion for the strength of the syntactic relation (see e.g. Zwicky 1978: 505, and below) the observation that other premodifiers in general cannot be separated from the rest of the NP suggests that the focusing modifiers are more loosely adjoined to the NP. ${ }^{12}$ This is supported by the observation

10 This may actually explain why frequency adverbs are included in the list of peripheral modifiers. Frequency adverbs and adjectives often express attitudinal meaning such as 'annoyance'. As adjectives, they are prone to early expression in the adjective string and can precede numerals, even when attitudinal meanings such as 'annoyance' are not involved (My briefcase contained the habitual three fountain pens, GoEx). For this reason Halliday (1994: 183) classifies them under the postdeictics. See also Davidse et al. (2008: 491 and passim) for the subjective meaning of frequency modifiers.

11 Quirk et al. (1985) do not include a slot for peripheral modifiers in their overview of the NP, although in the chapters about adverbs, they do recognise that adverbs can modify an NP (see Quirk et al. 1985: 450-2).

12 Note, however, that predeterminers can also float (see Sportiche 1988): The girls are all pretty unhappy (BNC). 
that even in the case of adjacency, the focusing modifier does not have a fixed position: it may attach to either the left or the right of the NP (see (26)-(27)).

(25) Separated focusing modifier:

The local council says he only has a licence for the fruit, and he needs another one to sell greens. (BNC)

(26) Left-adjacent focusing modifier:

The measurements I have given are only a rough guide. (BNC)

(27) Right-adjacent focusing modifier:

this is a rough guide only. (BNC)

Moreover, in many syntactic contexts, the peripheral modifier can be analysed as a sentence-level modifier rather than as a part of the NP. This can be illustrated by examples like (28), which are open to the two analyses in (29) and (30).

(28) Body language is probably the most important visual cue. (BNC)

(29) $[\mathrm{NP} P \mathrm{Pm} \quad[\mathrm{D} \quad[\ldots \quad[\mathrm{N}]]]]$

$\left.\begin{array}{l}\text { probably the most important visual clue } \\ \text { [AdvP } \\ \text { probably }\end{array}\right] \ldots\left[\mathrm{NP}\right.$ D $\begin{array}{l}\mathrm{D} \\ \text { the most important visual clue }\end{array}$

Still, an analysis along the lines of (30) is not always an option. In (31)-(32), the peripheral modifier follows a preposition. This suggests that the adverb perhaps is part of the NP that is the complement of the PP. The idea that in this construction the adverb syntactically belongs to the NP is supported by the semantics: in the examples (31)-(32) perhaps only has semantic scope over the NP inside the PP. In (31), perhaps is used to express doubt about whether the referent is indeed 'the most difficult aspect', rather than the analysis or the inclusion of an analysis. In (32), perhaps is used to question the felicity of the description 'extravagance' for what is going on. The rest of the clause is fully asserted.

(31) The main concern of this chapter is to complete the description of intonational form, including analysis of perhaps the most difficult aspect ... (BNC)

(32) I saw a lot of old friends, and wore a dashing outfit purchased at perhaps an extravagance in a London second hand shop. (BNC)

A second construction in which the peripheral modifier is not a sentence-level adverb, but forms a genuine part of the NP, is illustrated in (33). When used as a sentence-level adverb, presumably is situated at a higher level than the temporal adverb yesterday (see Ramat \& Ricca 1998: 192 for an overview of adverbial layering in different theories), and the former should occur to the left of the latter, on the basis of the iconic principle that lower-order adverbs are put closer to the verb (see Pullum \& Huddleston 2002: 576). The reason that we have the opposite order here is because presumably is operating at the lower NP rank. This is supported by the semantics: it is not the fact that a bird was seen several times which is modalised by presumably, but rather the claim that it was the same bird each time.

(33) yesterday presumably the same bird was also seen several times in the area of the Visitor Centre (GoEx) 
Appositions are a third construction where the adverb can only be associated with the $\mathrm{NP}$, as illustrated in (34). ${ }^{13}$ If the apposition is considered as an NP (and not as an elliptical clausal structure), then the adverb arguably is best represented as a peripheral modifier.

(34) Thus Baudelaire, arguably the godfather of aesthetic modernism, broke with the foundationalist assumptions of realism to celebrate the transitory, the fleeting, the contingent. (BNC)

Yet another argument for the proposition that peripheral modifiers form a genuine part of the NP comes from examples like (35)-(38), with what could be called a 'proleptic determiner'. In these examples, often though certainly not always from spoken data, the article is expressed twice, before and after the peripheral modifier.

(35) that means Google will become an even a greater gatekeeper to media company content than it already is (GoEx)

(36) With a perhaps a single teacher visit to a site armed with a digital camera and notebook followed up by a few simple web searches we can take our pupils on some pretty interesting journeys beyond the four walls of the classroom. (GoEx)

(37) Floating pennywort, however, is a presumably a winter hardy species, surviving reasonably low temperatures. (GoEx)

(38) Anderson's column became the possibly the most-quoted and most-reprinted in the area of agriculture publishing. (GoEx)

The basis for interpreting this kind of double expression of the article as evidence of the status of the peripheral modifier is as follows: most (non-pronominal) NPs start with an overt determiner. The slot in front of the determiner, where peripheral modifiers occur, need not be filled: contrary to what is the case with many determiners, the expression of a peripheral modifier is not obligatory. As a consequence, determiners are far more prominent at the token-level than peripheral modifiers, and as such cognitively mark the start of a noun phrase (see Hawkins 2004: 86-93). This is corroborated by examples like (39)-(41) from spoken language, which show that a successful realisation of a noun phrase often follows a series of false starts with just the determiner. In such cases the speaker executes an NP, but needs extra processing time to fully realise it lexically, and provisionally sets up the syntactic contours of a default NP (see Blanche-Benveniste 1997: 87-90 for this strategy of first setting up an embryonic version of a syntagm, and then retouching it via various iterations). The construction in (35)-(38) is then a compromise (or confusion) between two patterns: one with a determiner as the start of the NP, and one with a peripheral modifier preceding the determiner. In other words: if

13 As one reviewer points out, this diagnostic may be too strong, as appositions occur with a wider range of adverbs, some of which do not qualify as peripheral modifiers, including negation not and temporal adverbs: e.g. Nelson Mandela, not a stickler for etiquette/until last year the world's most famous retiree/. . . (examples provided by the reviewer). In the remainder of this article, more weight will be given to diagnostics 1 and 4 , and especially diagnostic 2 , rather than 3 . 
the language user decides to modalise the NP with a peripheral modifier after having expressed a determiner as part of the syntactic contour of a default NP, the speaker's only option is to add a supplementary determiner after the peripheral modifier. This is further evidence that the peripheral modifier belongs to the noun phrase.

(39) An absolutely diabolical situation because then the the the local authorities that have continued to avoid doing what they ought to have done will be rubbing their hands with glee. (BNC)

(40) I feel that we do need a a a a a framework, with a with a supply into Europe. (BNC)

(41) Because I have got this this this creamy shirt. (BNC)

If we consider the peripheral modifier as a genuine part of the NP (following Payne \& Huddleston 2002, and preceding discussion in this article), the question then is why they may occur in floating position, separated from their semantic complement. As adjacency is the default option, and according to some even a necessary condition, for (immediate) constituency (see Robinson 1970; Croft 2001; Evans \& Levinson 2009: 440-2), and as NP premodifiers as a rule do not float, one could argue that the floating peripheral modifiers are syntactically outside the NP, while adjacent peripheral modifiers are inside the NP.

There are at least two ways to accommodate this problem. The first is to assume floating modifiers are adjacent in the underlying structure, and that the floating position is (transformationally) derived. The second option is to assume only the adjacent modifiers are integrated in the NP, and that the floating position is a different construction altogether. The latter position is taken in this article, in line with the basic tenets of a usage-based approach, which is reluctant to accept syntactic transformations. What we see in Present-day English is a snapshot of a diachronic process in which peripheral modifiers are gradually becoming integrated in the NP. As will be shown in the remainder of this article, peripheral modifiers are increasingly used in the slot in front of the determiner.

4 The diachronic origin of peripheral modifiers: reanalysis in Modern English

Historically, peripheral modifiers started out as sentence-level modifiers, but over time, during the Modern English period, they have been absorbed in the NP.

Such a process is not uncommon cross-linguistically, and is known as 'reordering to adjacency', the tendency by which semantic association diachronically leads to linear contiguity (see Harris \& Campbell 1995: 220-4, 237). This extension of the NP to include a slot for peripheral modification is just one step in the diachronic process in which the (West) Germanic NP, with separate slots for various kinds of modification, is crystallising over time (see Himmelmann 1997; Van de Velde 2009b, c).$^{14}$ Other modifiers that are currently well integrated in the NP have not always formed part of the NP. In Van de Velde (2009b) it is shown how in the West Germanic languages

14 This development may not be restricted to (West) Germanic (see Heine \& Kuteva 2007: 84-6, 279-87). 
quantifiers have become incorporated in the NP over time, with a still ongoing decrease in their use in floated positions. Something similar is currently underway with the peripheral modifiers, which gradually enter the NP.

The most typical - that is, most frequent and formally least marked - instances of peripheral modifiers are the focusing modifiers, as in (11). Tracing the diachronic development of the latter elements may reveal how and when the peripheral modifier slot emerged.

In her discussion of focusing modifiers, Traugott (2006) shows that they tend to derive from predicate adverbs, e.g. a manner adverb (see (42)). When these adverbs are reanalysed as focusing modifiers (see (44)), probably through ambiguous examples like (43), they enter into a semantic relation with an NP (or another phrase, see below), but this is not immediately recognised in the word order. As usual, formal changes lag behind semantic changes (see Francis \& Yuasa 2008 and references cited therein). To this day, English allows peripheral modifiers that are associated with NPs to occur in 'floating position', as in (44), where even semantically belongs to the NP the jaw bones .... This results in synchronic gradience: a proportion of the peripheral modifiers floats, another proportion does not. Underlying this synchronic gradience is a diachronic trend (as a quantitative corpus survey shows, see below): floating peripheral modifiers are losing ground to the NP-adjacent peripheral modifiers, as in (45). The chronological order is thus $(42) /(43)>(44)>(45)$, though the stages do not, of course, discretely follow one another.

(42) Pe barons portiond pe lond euen pam bituene (c. 1330, R. BRUNNE Chron. (1810) 51, $O E D$ s.v. even, $a d v$.)

'The barons divided the land equally between them.'

(43) These sweet thoughts, doe euen refresh my labours (1610, SHAKES. Temp. III. i. 14, $O E D$ s.v. even, $a d v$.)

(44) and concluded the horrid sport by kicking and mangling the heads, cutting of the lips, cheeks, ears, and noses; they even took out the jaw-bones, which they smokedried, together with the right hands, to carry home, as trophies of their victory (1796, STEDMAN Surinam II. xx. 111, OED s.v. smoke-dry [context added])

(45) The tone of insolent superiority assumed by even the gutter urchins. (1863, F. A. KEMBLE Resid. in Georgia 11, OED s.v. even, $a d v$.)

The shift from manner adverb modifying a VP to a focusing modifier modifying an NP may seem like rather a big leap, as it involves a reanalysis of the constituency relations. Still, this course of events is not unprecedented. Vincent (1999) has extensively argued that prepositions, which have come to form a syntactic unit with NPs $(P+N P)$ in most European languages, originated as free-standing sentence particles. His analysis draws on historical data from the Romance languages, but the arguments carry over to Germanic as well.

According to Traugott (2006: 344), focusing modifiers are primarily a Modern English phenomenon, though earlier attestations can be found. She argues that their emergence is part of a more encompassing change in English, whereby adverbial resources increase dramatically. This observation goes back to Swan (1988: 538), who 
noted that over time 'speaker comments have become increasingly adverbialized' (see also Nevalainen 1994: 257). The same holds for closely related languages such as Dutch and German. A corpus study on Dutch (Van de Velde 2009b: 298-309) reveals that in this closely related language the first peripheral modifiers are indeed focusing modifiers and that they arise in the same period as English (see also Hoeksema 2002). For German as well, the rise of focusing modifiers seems to be an early modern development. In a case study on selbst, Eckhardt (2001: 402) dates the reanalysis from intensifying selbst to focusing modifier to 1600 .

Focusing modifiers are syntactically promiscuous, combining with all sorts of phrases (see Pullum \& Huddleston 2002: 586-7). As shown in (46)-(48), they indiscriminately attach to subordinated clauses, PPs, NPs, etc.

(46) We haven't signed anyone yet, only because it's got to be the right player. (BNC)

(47) Mr Kinnock has to be protected from questions because he is likely to give the wrong answers, even about specific Labour policies he is supposed to know by heart. (BNC)

(48) She had the beautiful skin of the islands, with hardly a wrinkle, except near the eyes, where the smile lines puckered the corners. (BNC)

As said, this semantic association is not necessarily reflected in the constituency relations: syntactically, the focusing modifier can still be an adverbial at the sentence level, rather than being integrated in the NP. ${ }^{15}$

This means the emergence of focusing modifiers as a new category in Early Modern English does not necessarily tell us when they were syntactically incorporated in the NP. As shown in (49), floating position for focusing modifiers with NPs is still possible in Present-day English, so on the face of it, it could look as if nothing has really changed historically: the very fact that such modifiers can float shows that they do not form an integral, inseparable part of the NP in Present-day English.

(49) A disease that only affects boys. (2001, Linedancer Mag. Oct. 61/2, OED s.v. only, adv., conj., and prep.)

Still, this is only true if one takes a categorical approach, with peripheral modifiers being consistently either inside or outside the NP. An alternative approach is to tackle the issue from a gradualist, diachronic perspective. New patterns do not emerge overnight, but can take some time to become entrenched in the speech community. The incorporation of peripheral modifiers in the NP is most likely a long-term diachronic process, with

15 Such a 'mismatch' (the word 'mismatch' is put between scare quotes as it betrays a European bias: constituency is probably not a universal property of languages; syntactic relations can be marked by other means as well (inflection, adpositions); see Croft 2001, Matthews 2007, Evans \& Levinson 2009: 440-2) of syntax and semantics is not restricted to the domain of focusing modifiers. Possessives also need not be used attributively (as a modifier or determiner of the possessee noun), but can be encoded predicatively or as an object as well (see Heine 1997: 45-76). Another domain where nominal features are not expressed inside the NP is deixis. What English encodes adnominally (again, glossing over the distinction between modifiers and determiners), can in other languages be realised adverbially at clause rank (see Diessel 1999: chapter 4), or as a predicate (see Dixon 2003: 69). And even in the case where a demonstrative does take the form of a pronoun, it is often encoded appositionally, forming a separate constituent from the noun phrase it semantically modifies (see Diessel 2008). 
old and new patterns coexisting in language use. In the English NP, such diachronic gradience (or 'gradualness') has been observed in the determiner domain: adjectives can shift to the class of determiners (certain, various ...), and this may result in a prolonged period of category gradience with elements falling in-between both classes (see Denison 2006, and, for quantitative corroboration, Van de Velde 2009a). If we extend this kind of gradience from categories to constructions (see also Rosenbach 2007), it may also account for the change in the syntax of peripheral modifiers, which are midway between a position outside and inside the NP. In the case of peripheral modifiers there appear to be increasing restrictions on the possible syntactic contexts that they can occur in. While it is true that peripheral modifiers can still be separated from their semantic complement, as illustrated in (49), not all patterns are grammatical anymore. In earlier periods, focusing modifiers that semantically have scope over subject NPs could still float away (see (50)), and this might be an indication that the floating position is in retreat.

(50) The eldest sone shall onlye enheryte his father. (1531, tr. C. St German Dyaloge Doctour \& Student (rev. ed.) I. vii. f. xx, OED s.v. only, $a d v$., conj., and prep.)

(51) Only the oldest son shall inherit from his father./* The oldest son shall only inherit from his father.

The pattern which provides the best evidence of the use of peripheral modifiers as genuine parts of the NP is when the NP is a complement of a PP (see above). It is, however, not clear how frequent the construction is. ${ }^{16}$ Due to the variation in the specific lexemes that constitute the construction [PP P [NP Pm ...] ], it is difficult to detect in corpora that are not syntactically annotated. Perusing the $O E D$ citation material suggests it is an Early Modern English innovation, with early instances of PP-internal focusing modifier only attested from the sixteenth century onwards, and of other focusing modifiers like even from the eighteenth century onwards (see (52)-(55)). Sentence adverbs other than focusing modifiers, like apparently, perhaps, etc. are of even later date (see below).

(52) Capercalze..lyues of only the tuigs or tendir branches of this [fir] trie. (1596, DALRYMPLE tr. Leslie's Hist. Scot. (S.T.S.) I. 39, OED s.v. twig, $n^{1}{ }^{1}$ )

'The wood-grouse lives off just twigs and soft branches of this tree.'

(53) I lying this night with only a rugg and a sheet upon me. (1667, PEPYS Diary 13 July, $O E D$ s.v. rug, $n .^{2}$ )

16 Intuitive judgments are not to be trusted. Taking the example of two closely related languages, it appears that linguists have long underestimated the frequency of this construction. In German, peripheral modifiers inside PPs are deemed ungrammatical by many scholars (see Bouma et al. 2007 for an overview), and indeed, they may be more marked than in Dutch or English. Still, they do occur. As early as the late nineteenth century, Wustmann (1896: 299) adduced numerous examples of this construction, although he normatively disapproved of it. Similar disapproval of the Dutch construction has been incurred by Zaalberg (1975: 22), who thinks it is a mid twentieth-century innovation due to influence from American English. Detailed corpus research has shown, however, that the construction is attested from Early Modern Dutch onwards (see Bouma et al. 2007: 17; Van de Velde 2009b: 301-9). 
Table 1. PP-internal peripheral modifiers in Modern English

\begin{tabular}{llcll}
\hline \hline Corpus & Period & Frequency & Corpus size & $\begin{array}{l}\text { Freq. / Million } \\
\text { tokens }\end{array}$ \\
\hline CEMET & $1640-1710$ & 2 & $1,943,392$ & 1.0 \\
CLMETEV & $1710-1780$ & 10 & $3,037,607$ & 3.3 \\
CLMETEV & $1780-1850$ & 76 & $5,723,988$ & 13.3 \\
CLMETEV & $1850-1920$ & 124 & $6,251,564$ & 19.8 \\
CB & Present-day E. & 137 & $5,354,262$ & 25.6 \\
Total & & 349 & $22,310,813$ & 15.6 \\
\hline \hline
\end{tabular}

(54) The first [Horse] will fret, gall, and be full of Warbles, with even the least Journey. (1737, BRACKEN Farriery Impr. (1757) II. 161, OED s.v. warble, $n .^{2}$ )

(55) ... when compared with the unanimated beauties of even the Venus de Medici. (1799, CORRY Sat. Lond. (1803) 60, OED s.v. unanimated)

To calculate how frequent the construction is with PP-internal peripheral modifiers in Modern English, a corpus search was carried out with the aid of the Abundantia Verborum software (Speelman 1997) on the string P + Adv + Article in the CEMET corpus and CLMETEV corpus, and, for Present-day English, in the written UK subpart of the COBUILD Corpus (CB). In the Regular Expression query, the P position allowed for one of eight frequent prepositions (at, by, for, from, in, of, on, with). The Adv position selected for words ending in $-l y([\wedge]+1 y)$. This excludes the focusing modifiers even and just, but includes others like only, barely, hardly, to ensure that focusing modifiers are represented. ${ }^{17}$ For the sentence adverbs, an additional search was run on the two frequent adverbs maybe and perhaps (clearly not captured by the -ly query), for fear of overlooking the starting point at which adverbs other than the focusing modifiers enter the slot for peripheral modifiers (and indeed, perhaps turns out to be one of the earliest adverbs to follow in the footsteps of the focusing modifiers). Spurious hits were manually weeded out.

The results are given in table $1 .^{18}$ As the corpus size for the different subperiods varies, the results have been normalised to occurrences per million words of running text. The drastic and steady upsurge in the frequency of the construction - a 25-fold increase during the whole Modern English period - is visualised in the bar chart in figure 1 , were the results have been indexed, setting the first period at $100 .^{19}$

17 As even and just are rather frequent focusing modifiers, and occur in the CEMET and CLMETEV already, including them in the corpus study would only strengthen the results reported below, that is: short adverbs are the first elements to enter the peripheral modifier slot and they have a high token frequency.

18 The results have been checked for statistical significance with a chi squared test on absolute frequencies compared to corpus size (see De Smet 2009: 1734 for a similar procedure). A test value of 99.0717 yields a p-value below 0.0001 .

19 The reason why the index does not simply multiply the value in the last column of table 1 by 100 is that the numbers have been rounded to the first decimal in table 1 , whereas the index was calculated on the unrounded numbers; similarly for table 2 and figure 2 . 


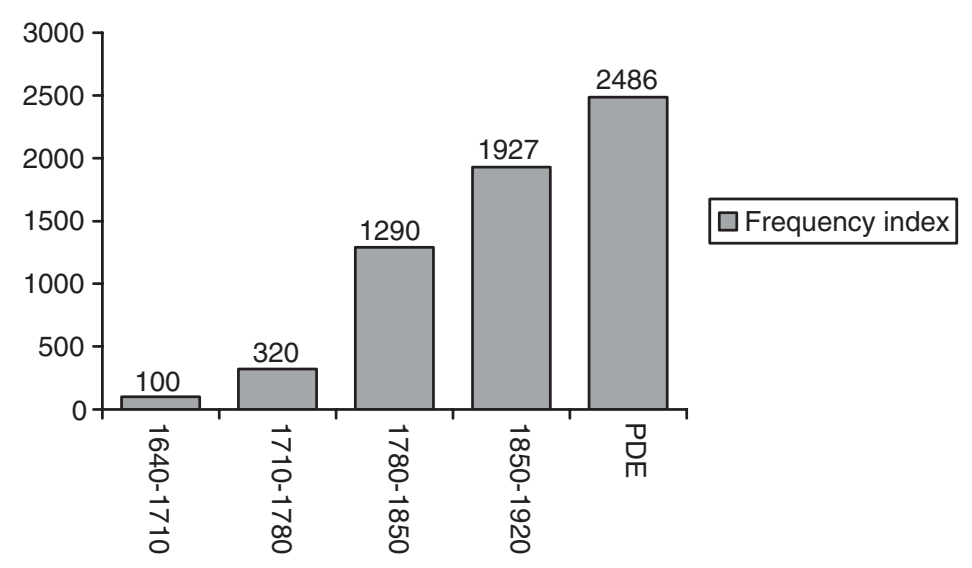

Figure 1. PP-internal peripheral modifiers in Modern English (indexed: 1640-1710=100)

The results in table 1 and figure 1 indicate that at the token level, more and more peripheral modifiers occur in the left-adjacent slot of the NP as time goes by. They do not make clear what kinds of elements (the type level) occur in the slot. In the next section, a closer look will be taken at the diachrony of the lexemes employed as peripheral modifiers.

\section{Extension by analogy}

When a new construction emerges, the group of possible lexemes that instantiate it may grow over time, by a process of analogical extension (see Harris \& Campbell 1995: 51, 97-119; Croft 2000: 148-56; Fischer 2007, 2008). An obvious example in the history of English is the grammaticalisation of complex prepositions of the type [P N P], such as by means of, in relation to, etc. Well-entrenched exemplar instances like in view of may analogically give rise to new coinages like in conformity with and by dint of (see Hoffmann 2004).

The same goes for PP-internal peripheral modifiers. Looking at the CEMET/CLMETEV/CB corpus data, it is clear the slot started out with focusing modifiers, which are to this day the most frequent instances, and only later became available for other kinds of sentence adverbs like apparently or perhaps. As in the OED citation corpus, the first example in the Modern English corpora consulted involves the focusing modifier only (see (56)), and it is by far the most common peripheral modifier in each period. Not until the end of the period 1780-1850 do we encounter other adverbs than focusing modifiers in the PP-internal slot (see (57)-(59)).

(56) I went into the market-place, with only a man and maid. (1625, CEMET)

(57) but continuing the same tone and manner, and with evidently the same feeling, she speaks of other cases of suffering, of some friend or neighbour (1832, CLMETEV) 
Table 2. Lexical variation in the peripheral modifiers

\begin{tabular}{llcl}
\hline \hline Corpus & Period & Types & Type/token ratio \\
\hline CEMET & $1640-1710$ & 2 & 1.0 \\
CLMETEV & $1710-1780$ & 3 & 0.3 \\
CLMETEV & $1780-1850$ & 12 & 0.2 \\
CLMETEV & $1850-1920$ & 13 & 0.1 \\
CB & Present-day E. & 19 & 0.1 \\
\hline \hline
\end{tabular}

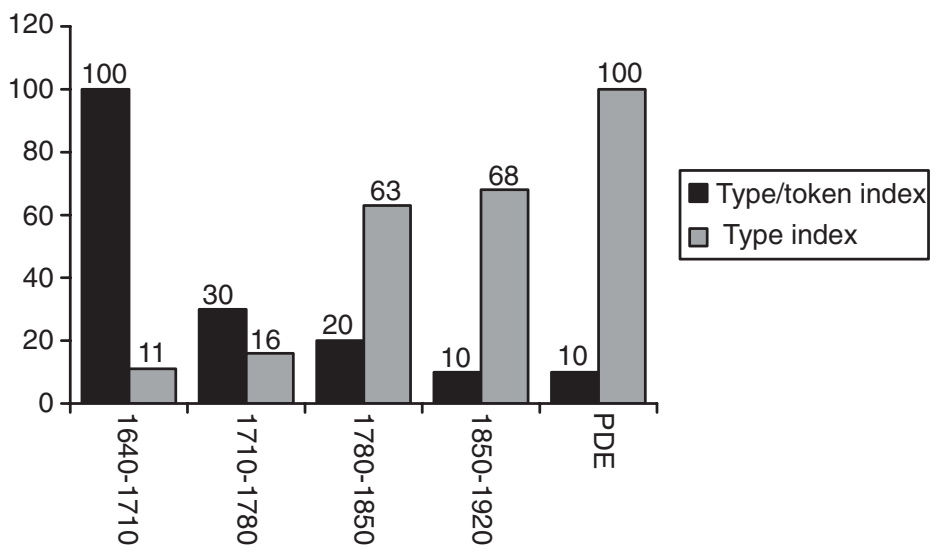

Figure 2. Lexical variation in the peripheral modifiers (indexed: $1640-1710=100$ for types; $\mathrm{PDE}=100$ for type/token ratio)

(58) it has seemed good to him to accomplish the greatest ends by apparently the most insufficient means (1842, CLMETEV)

(59) 'Is he not your friend?' said I, turning my eyes from the fire to his face, with perhaps a slight touch of those feelings he assigned to another. (1848, CLMETEV)

Table 2 shows that the number of different lexemes at the type-level increases over time: as the construction rises, so does the variation in the different types that occur in the construction. Still, as becomes clear from the decreasing type/token ratio (last column), there remains a core group of prototypical peripheral modifiers. In other words: more and more different adverbs are allowed in the peripheral modifier slot, but this does not occur at the expense of the popularity of the traditional peripheral modifiers like only. This is visualised in figure 2, where both the types and the type/token ratio are indexed (types: $\mathrm{PDE}=100$; type/token ratio: $1640-1710=100$ ).

If we consider the length of the modifiers in relation to the types, a pattern can be observed which is represented in figure 3. Not unexpectedly, there is a Zipfian inverse correlation (see Pustet 2004) between the length of the adverb (measured crudely in 


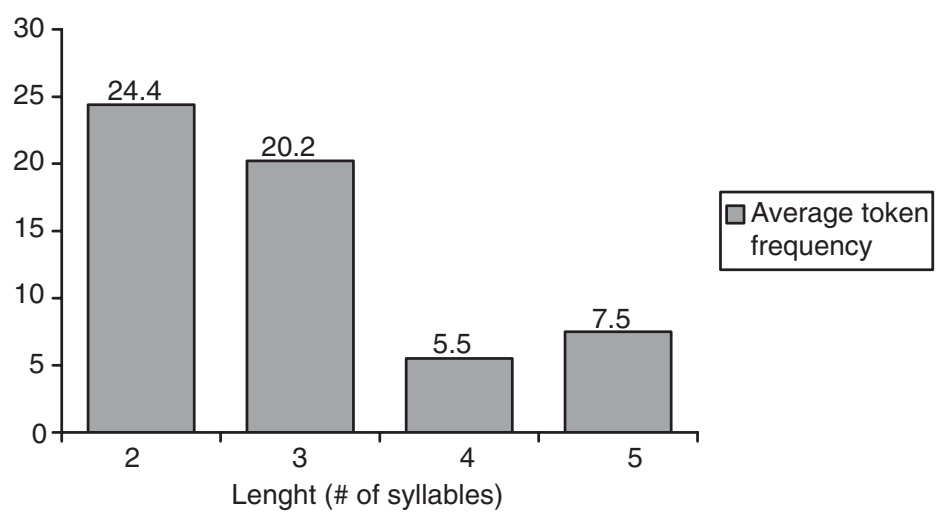

Figure 3. Relation between phonetic substance (syllable length) and average token frequency

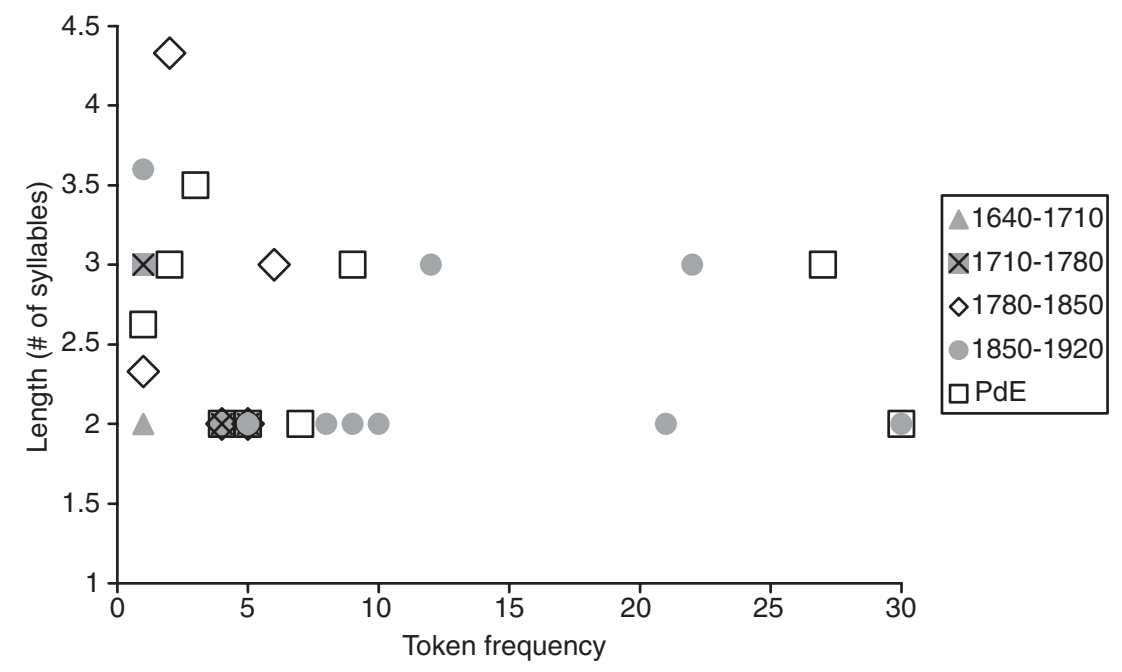

Figure 4. Relation between token frequency and average syllable length

number of syllables) and the average token frequency of the lexemes of this length. Put simply, the more frequent the adverb is, the shorter it will predictably be. ${ }^{20}$

The numbers in figure 3 become more interesting if we look at the diachronic stability of this inverse correlation. The results are shown in figure 4, where for each value of the token frequency $(1,2,3 \ldots 29,30+),{ }^{21}$ the average syllable length of the according types is given per time period. As the token frequency increases over time (see table 1), high values on the $\mathrm{x}$ axis are only attested in the most recent periods.

20 The reason why there are no peripheral modifiers of length 1 is merely a consequence of our limited query, which was not accurate enough to select one-syllable focusing modifiers like just. Note also that the trend is not perfect, as adverbs of length 5 are on average more frequent than adverbs of length 4 .

21 The value $30+$ should be read as: ' 30 or more'. 
The most interesting aspect of figure 4 is where the results deviate from the expected correlation between token frequency and phonetic substance in figure 3 . Though there is certainly up-left to down-right clustering, which shows that the Zipfian tendency observed in figure 3 remains stable through time, the correlation is far from perfect. In more recent periods (1850-1920 and PDE: the squares and circles in the graph), longer adverbs are more frequent than expected. This can be taken as supporting evidence for the idea that there is indeed type extension going on: in the light of figure 4 , the decreasing type/token ratio seen in table 2 may be interpreted as the growing popularity of the well-entrenched core members of the category (which are short), next to a simultaneous increase in type diversity (which means there are also longer forms).

\section{Further extension: transparent free relatives}

The data presented in section 5 suggest there is an increase in types, which has been hypothesised to be the result of analogical extension. As focusing modifiers became 'entrapped' in the position at the left periphery of the noun phrase they modified (due to reordering to adjacency, see above), language users began to perceive this position as a slot for subjective modification. ${ }^{22}$ Using the focusing modifiers as exemplars, other subjective adverbs joined the group of peripheral modifiers. ${ }^{23}$ In this section, we will substantiate this hypothesis of analogical extension by looking at a specific kind of peripheral modifier. A satisfactory account of these can only be given if we assume they are analogically built on the model of other peripheral modifiers.

The construction at issue is rather complex, and goes by the name of 'transparent free relatives', a term introduced by Wilder (1999) for a phenomenon that had earlier been noticed by McCawley (1988: chapter 22, with reference to work by Kajita). An example is given in (60).

(60) Under microscopic examination, what appeared to be tiny worms were discovered inside the rock. (GoEx)

In (60) the subject (what appeared to be tiny worms) takes the form of a so-called free relative, a relative clause without an antecedent (see Huddleston \& Pullum et al. 2002: 1068-79). At first sight, there is nothing odd about the free relative in (60). It appears not to differ from other free relatives, like the ones in (61)-(62).

(61) What you just said is contradictory. (GoEx)

(62) This isn't what I ordered. (GoEx)

22 This may have been helped by the fact that at the clause rank too, subjective modification is often (though certainly not always) realised in the left periphery (e.g. fortunately, he came).

23 Of the peripheral modifiers listed in (11)-(18), the frequency adverbs were less clearly subjective in nature (though see footnote 9). Interestingly, frequency adverbs are rare in the PP-internal peripheral modifier slot. In our corpus search, the only example (with the adverb mostly) is from PDE. 
Still, looking more closely at (60), it turns out that it has some interesting syntactic properties. For one thing, it triggers plural agreement on the verb (were). This is odd, as free relatives are normally invariably singular (see (63)).

(63) What you just said is/*are contradictory.

In the 'normal' free relatives exemplified in (61)-(62) the grammatical features of the free relative as a whole are determined by the free relative pronoun what, which is indeed singular, whereas the grammatical features of the free relative in (60) are determined by its right-peripheral NP tiny worms, which functions as the predicate nominal inside the free relative. Indeed, there are other features as well for which this right-peripheral element seems to be the controller. Take for instance definiteness. Whereas transparent free relatives of the type in (60) can occur in a presentative construction, which selects for indefinite NPs (see Lyons 1999: 236-46), other free relatives cannot, as shown by the difference in grammaticality of (64) and (65). This difference can be explained by assuming it is the (definite) free relative pronoun what that determines the definiteness value of the whole free relative in (65), and it is, by contrast, the indefinite rightperipheral NP a hard-boiled egg that determines the definiteness value of the whole free relative in (64).

(64) Our first meal began with an amuse gueulle that was quite extraordinary. There arrived what appeared to be a hard-boiled egg. (GoEx)

(65) ?? Our first meal began with an amuse gueulle that was quite extraordinary. There arrived what I ordered.

For other grammatical features as well, such as animacy, negative polarity item licensing, etc., transparent free relatives rely on this right-peripheral NP, which Schelfhout et al. (2004) have conveniently called the CONTENT KERNEL. ${ }^{24}$ One needs to look 'through' the free relative pronoun, inside the free relative clause, all the way to the right-peripheral content kernel, so to speak. Thus, justifying the construction's name transparent free relative.

To account for the syntactic behaviour of transparent free relatives, a number of analyses have been put forward, most of which approach the construction from a synchronic perspective (see Schelfhout et al. 2004 for an overview). A common analysis is to view the construction as a fusion of two constructions: a mother construction onto which another construction is 'grafted'. The locus of the graft - the CALLus, as it is technically called - is the overlapping constituent in both constructions. Under such an analysis, which has been proposed in full detail by Van Riemsdijk (2000, 2001), example (60) has a mother construction in the form of a clause (under microscopic examination, tiny worms were discovered inside the rock), and a graft in the form of a free relative (what appeared to be tiny worms). The shared part of both clauses (the NP tiny worms) is used as a callus for the graft. In other words, one branch of the syntactic

24 In fact, the right-peripheral element need not necessarily be an NP, so it is perhaps more accurate to speak about 'right-peripheral XP', as Schelfhout et al. (2004) do. 
tree of the clause under microscopic examination, tiny worms were discovered inside the rock sprouts a whole clausal tree itself (what appeared to be tiny worms).

This basic idea of a merger of two syntactic trees is taken up by Van de Velde (2009b, c), adding a diachronic perspective, and arguing that it may be the result of a reanalysis: the content kernel comes to be interpreted as the head of the construction, with the rest of the free relative as a premodifier. If this interpretation is applied to the example in (60), we arrive at a structure like (66), where the string what appeared to be functions as a premodifier of the content kernel noun worms. ${ }^{25}$

(66) [NP [what appeared to be] [tiny [worms]]]

The question is what kind of premodifier what appeared to be exactly is. Example (64) makes clear that it is a peripheral modifier. It occurs in front of the determiner, and it has the appropriate semantics: it expresses evidential meaning, which belongs to the interpersonal domain. Moreover, it occurs frequently in the proleptic determiner construction mentioned in section 3 above (see (67)-(68)).

(67) the camera captured the image of a what appeared to be a male vampire at rest (GoEx)

(68) the whole structure was balanced on a what could only be described as a metal ball (GoEx)

Given that transparent free relatives are peripheral modifiers, example (64) can be represented as follows:

$\left.\begin{array}{lllll}\text { (69) }[\mathrm{NP} & {[\mathrm{Pm}} & {[\mathrm{D}} & {[\mathrm{A}} & [\mathrm{N}]]]\end{array}\right]$

What may have happened here is that other peripheral modifiers functioned as exemplar constructions, on the basis of which free relatives with the appropriate semantics were restructured. This is a familiar mechanism, which can be seen at work in the rise of quantifiers like a lot of. Originally, NPs like a lot of problems consisted of the head a lot and a PP postmodifier of problems, but by analogy with other quantifiers like many, a lot of was reinterpreted as a quantifier (see Traugott 2008a, b; Brems 2010). The reanalysis of the syntactic structure of the free relative can only take place once the slot for peripheral modifiers is sufficiently familiar to language users, as it needs the adverbial peripheral modifiers as an exemplar. Contrary to the adverbs that function as peripheral modifiers, the transparent free relatives cannot penetrate into the NP from a floating position, but are inserted on the basis of analogy with other peripheral modifiers.

If analogical extension is indeed the mechanism by which transparent free relatives have originated, we may expect them to diachronically follow in the slipstream of other, simpler peripheral modifiers. This is, however, not an easy question to investigate in a

25 This kind of reanalysis whereby 'clause fragments' come to express attitudinal meaning is not restricted to transparent free relatives, but can also be seen at work in constructions like two full years with God knows how many people involved (BNC), and many other cases (see also Lakoff 1974, who uses the term SYNTACTIC AMALGAMS). 
Table 3. Raw frequency of free relatives - non-transparent and possibly transparent

\begin{tabular}{llllr}
\hline \hline Corpus & & \multicolumn{2}{l}{ Non-transparent } & Possibly transparent \\
& Period & FR & FR & Total \\
\hline CEMET & $1640-1710$ & 98 & 1 & 99 \\
CLMETEV & $1710-1780$ & 129 & 29 & 158 \\
CLMETEV & $1780-1850$ & 244 & 68 & 312 \\
CLMETEV & $1850-1920$ & 194 & 112 & 306 \\
CB & Present-day E. & 204 & 162 & 366 \\
Total & & 869 & 372 & 1241 \\
\hline \hline
\end{tabular}

corpus. First, the transparent free relatives show considerable variation in their form. The only element they all share is the free relative pronoun what, which is highly polysemous in English. Second, in the overwhelming majority of cases, there are no syntactic clues to determine whether the free relative is transparent or not. The number agreement criterion requires the free relative be in the subject position, but due to their syntactic complexity, free relatives are more likely to function as objects, rather than as subjects. Subjects are mostly thematic and syntactically simple (see Du Bois 1985), unless they are used in a presentative construction, but free relatives in presentative constructions are not very frequent in our corpus. Still, a corpus study may yield valuable, though indirect, insights into the diachrony of transparent free relatives.

In table 3 , the results of a search for free relatives are presented. To limit the number of (spurious) hits, the query was limited to a combination of a preposition (again, the following set of frequent prepositions was included: at, by, for, from, in, of, on, with), the pronoun what and one of the forms of the verbs be, have, seem and appear. By looking only for PP-internal what, irrelevant hits with the interrogative pronoun (e.g. what is the matter?) are automatically excluded. The obvious drawback of this procedure is that only those free relatives are sampled where the context as a rule does not provide formal proof of their possible transparency, as PP-internal free relatives can never trigger number agreement on the main verb and can never be used as the subject in presentative constructions, etc. But what we do have is a distinction between free relatives that are definitely not transparent, like (70), and free relatives that may be transparent, like (71). The latter examples form what is known as BRIDGING CONTEXTS (see Evans \& Wilkins 2000; Heine 2002), contexts where both readings are possible, and where the locus of reanalysis is situated.

(70) It is unwise to guess about performance criteria or to choose from a menu, as these usually represent no more than a picture of what is fashionable at the moment. (CB)

(71) The first shot showed three bodies, side by side in what appeared to be a desert. (CB)

In some cases, there are strong indications that we do in fact have a transparent free relative. Thus, whereas normal free relatives can be substituted by a pronoun (this or that), the transparent free relative in (73) cannot. The reason is that the whole PP (in what seemed no time at all) functions as a time adverbial, and needs a temporal noun 


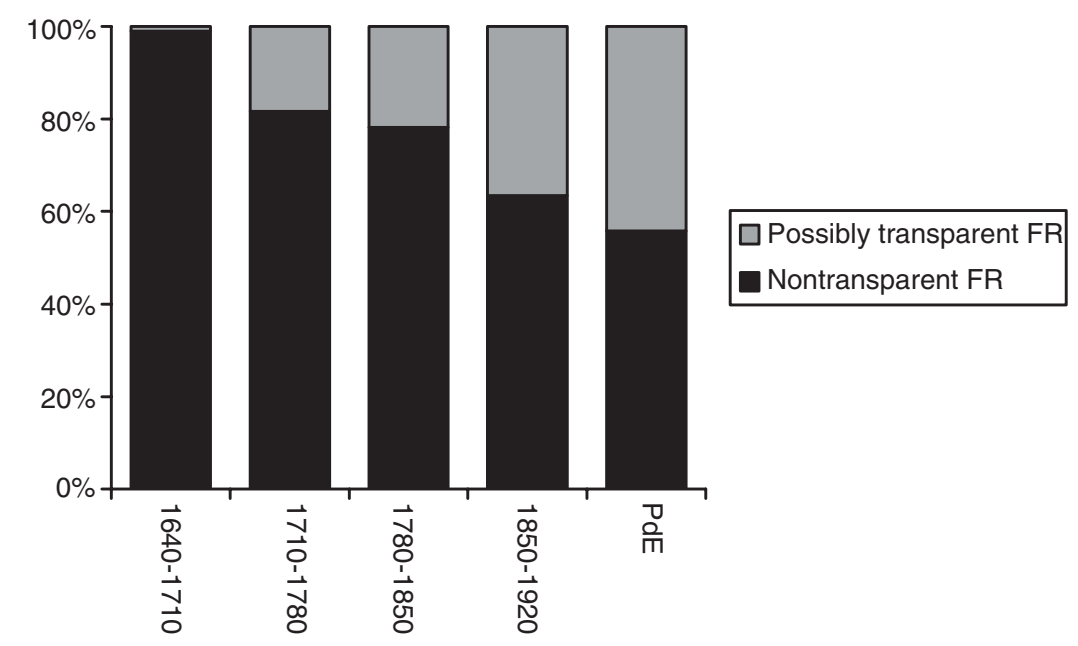

Figure 5. Free relatives - nontransparent and possibly transparent (in percentages)

like hour or time to express this meaning. The free relative needs to be transparent so that the content kernel no time is visible for elements in the main clause.

(72) After all he bore no responsibility for [what had happened the day before]=this. (CB)

(73) In [what seemed no time at all $]_{\neq \text {this }}$ Anthony found himself steering the Morris towed behind the truck. (CB)

If the ratio between possibly transparent free relatives like (71) and patently nontransparent free relatives like (70) turns out to increase, this would support the idea that free relatives were at some point reanalysed and became transparent. This would not tell us, however, when the reanalysis precisely took place, as each individual bridging context can still be conservatively interpreted as representing the old (i.e. non-transparent) meaning.

So if we turn to the data we do see a clear increase in bridging contexts (table 3 and figure 5), the first example of which, given in (74), occurs in the earliest period analysed (1640-1710). ${ }^{26}$ The first example where the context provides a clue for the transparency is, however, of considerably later date (1912; see (75)). The relative chronology is consonant with our hypothesis about analogical extension of the peripheral modifiers.

(74) yet she has a general Notion of what is call'd a fine Gentleman (1692, CEMET)

(75) Colonel Gracie came to the surface after holding his breath for what seemed an eternity. (1912, CLMETEV)

${ }^{26}$ Chi squared $=101.6740 ; \mathrm{p}<0.0001$. A Gamma test has been used to measure the correlation between the ordinal independent variable 'period' and the dependent variable 'transparency', which as a binary nominal variable can be treated as ordinal. Test results indicate a significant correlation $(\Gamma=0.4413$; asymptotic standard error $=0.0383$ ). 
Table 4. Internal complexity of the possibly transparent free relatives

\begin{tabular}{llcccc}
\hline \hline Corpus & & $\begin{array}{l}\text { Complexity } \\
2-3\end{array}$ & $\begin{array}{l}\text { Complexity } \\
4-5\end{array}$ & $\begin{array}{l}\text { Complexity } \\
6-8\end{array}$ & Total \\
\hline CEMET & $1640-1710$ & 1 & 0 & 0 & 1 \\
CLMETEV & $1710-1780$ & 26 & 3 & 0 & 29 \\
CLMETEV & $1780-1850$ & 42 & 23 & 3 & 68 \\
CLMETEV & $1850-1920$ & 65 & 39 & 8 & 112 \\
CB & Present-day E. & 69 & 79 & 14 & 162 \\
Total & & 203 & 144 & 25 & 372 \\
\hline \hline
\end{tabular}

In the previous sections it has been argued that the diachronic accretion of peripheral modifiers with increasing complexity - from short focusing modifiers (only, hardly) over other kinds of sentence adverbs (possibly, perhaps) to transparent free relatives (what appeared to be) - is the result of analogical extension. Additional support for this idea comes from the observation that transparent free relatives are themselves becoming more complex over time. As the use of simple transparent free relatives such as (76) became well entrenched in English, more elaborate constructions such as (77) arose. $^{27}$

(76) The English retaliated in what seemed an insulting way. (CB)

(77) Lady Rice, erstwhile mistress of what was now described in guide books as a stately home. (CB)

This 'complexification' of transparent free relatives is illustrated in table 4 and figure 6 , where the internal complexity is approximated rather simplistically by counting the number of words that precede the content kernel. ${ }^{28}$

7 An onomasiological and constructional approach to language change

In the preceding sections, it has been argued that the NP grew a new branch in its syntactic tree during the Modern English period. Preceding the determiner (and the predeterminer) there is a slot for peripheral modifiers. The slot is still 'under construction', as the slot fillers are still capable of forming their own constituent as floating modifiers at the clause rank. There is nevertheless a clear trend towards nonfloating use.

The diachrony of the peripheral modifiers is not very well covered in the literature on changes in NP syntax. Adamson's pioneering study on leftward movement and subjectification in the NP (Adamson 2000) does not address the rise of peripheral modifiers. Of the wide array of peripheral modifiers, only the focusing modifiers have been discussed in grammaticalisation theory (see e.g. Traugott 1995, 2006). Other

27 See Van Bogaert (2010: 415-16) for the idea that entrenchment and higher frequency can lead to more variation on the lexical form of a construction, rather than to fixation.

${ }^{28} \Gamma=0.3606$; asymptotic standard error $=0.0696$. 


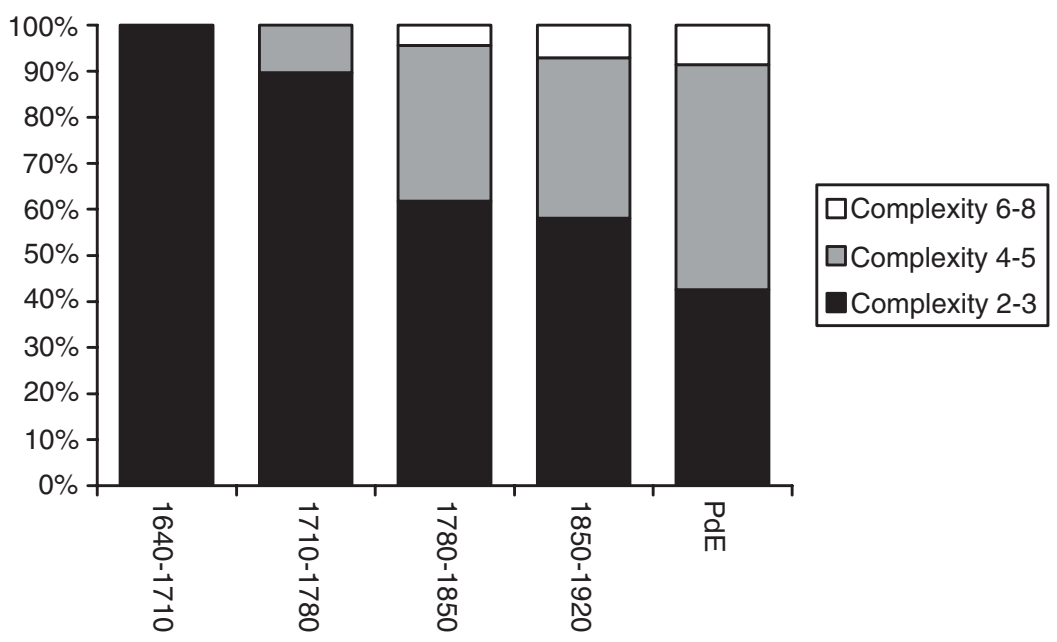

Figure 6. Internal complexity of the possibly transparent free relatives (in percentages)

epistemic modifiers such as I think have been discussed in Thompson \& Mulac (1991), Traugott (1995), Brinton (1996, 2008), but not in the context of NP modification, and mainly from a semasiological perspective: what is investigated is the change in meaning, and the corresponding change in the form of a set of particular lexical items. Such an approach, however, runs the risk of missing an important generalisation. The change does not only affect the individual lexemes, but rather the abstract syntactic template of the NP. Thus, what is needed here is an onomasiological rather than a semasiological approach. ${ }^{29}$ These approaches trigger different questions. To take the example of the focusing modifier even: in a traditional semasiological approach (such as Traugott 2006), the question is what semantic and syntactic changes the adverb even underwent when it became a focusing modifier. In an onomasiological approach, the question is what lexemes and constructions can or could be used in the domain of interpersonal modification of the NP. The latter question will link the changes in even with those in other peripheral modifiers, like the epistemic sentence adverbs and the transparent free relatives.

The onomasiological perspective meshes with a recent trend in grammaticalisation theory which fully recognises the importance of lexically underspecified constructions. The idea that grammaticalisation processes do not affect single lexemes, but rather constructions, is now well accepted (see Croft 2000: 62, 156, 163; Heine 2003: 575; Traugott 2003), but originally the notion of construction was only applied to lexically specific strings, as Trousdale (2008: 303-4) notes. The idea that grammaticalisation may affect (let alone result in) more abstract, i.e. lexically underspecified, constructions has until recently been contested. It was advocated by Bybee (2003: 146, 2007),

${ }^{29}$ See also Croft (2010) for the idea that an onomasiological approach may yield insights that are difficult to obtain with a semasiological approach. 
but was opposed to by Traugott (2003) and Noël (2007). Recently, however, Traugott seems to have reassessed her previous stance, and now agrees that lexically underspecified constructions can be the result of grammaticalisation processes. As a result, grammaticalisation has been re-sorted (at least by some) under the more general heading of 'constructionalisations' (see e.g. Traugott 2008a, b). A Construction Grammar approach may provide additional insights into problems that grammaticalisation theory has long been struggling with. Two such problems are (i) the issue of scope decrease/increase and (ii) the role of frequency.

Concerning (i), there is some discussion about whether grammaticalisation involves scope decrease or scope increase, or both. Traditionally, scope decrease was seen as a symptom of grammaticalisation (see Lehmann 1985), but later studies have shown that grammaticalisation often results in scope increase (see e.g. Tabor \& Traugott 1998). This is an idea that is echoed in the generativists' view on grammaticalisation, where lexical elements climb up in the syntactic tree (see Roberts \& Roussou 2003). ${ }^{30}$ In the case at hand, the scope problem also applies. The rise of interpersonal adverbs normally results in scope increase, but the change of even from VP adverb (a clause constituent) to focusing modifier of the NP seems to implicate scope decrease. Still further, note that the peripheral modifiers have wide scope within the NP.

Concerning (ii), the role of frequency in grammaticalisation processes, it is not clear whether grammaticalisation always goes hand in hand with high frequency. Normally, grammaticalisation of an element boosts its token frequency (see e.g. Bybee 2003), but as Hoffmann (2004), Mair (2004) and Brems (2007) have shown, this is not always the case. Hoffmann discusses the grammaticalisation of complex prepositions like in conformity with and by dint of, whose limited frequency apparently does not preclude grammaticalisation. Similarly, Brems discusses the rise of quantifiers like a smidgen of or a scintilla of, which are composed of rather infrequent nouns. Both cases are hard to describe if we focus on the changes of the individual examples, one by one. Only if it is recognised that there is an abstract construction [Complex Preposition $\mathrm{P}+\mathrm{N}+\mathrm{P}$ ] or [Quantifier $\mathrm{a}+\mathrm{N}_{\text {Small entity }}+$ of] and/or a high-frequency exemplar (e.g. in front of and a lot of) that triggers analogical extension, can we arrive at an insightful account. A constructional approach is also needed in the diachronic account of the peripheral modifiers discussed in the present article. Some peripheral modifiers, such as the transparent free relative in (78), are not very frequent in the lexical form they incidentally happen to appear in, and as such are not likely to grammaticalise 'by themselves'; in contrast, a more frequent combination like may be could more easily crystallise into a sentence adverb (maybe).

${ }^{30}$ Various solutions have been suggested to settle this paradox, some dismissing the instances with scope increase as not involving real grammaticalisation, some making a distinction between early and late grammaticalisation corresponding with scope decrease and increase respectively, some arguing that scope increase/decrease is not a good criterion, or at least not a one-size-fits-all criterion for all kinds of grammaticalisation, and some questioning the accuracy of the syntactic analysis (see Fischer 2007: 184, 260; 2008). 
(78) ... whose reasoning faculties have been confounded or destroyed by what is most erroneously termed learning. (1813, CLMETEV)

An adequate explanation of how a language user can correctly interpret (78) as a peripheral NP modifier calls for the recognition of the analogical power exerted by other, simpler peripheral modifiers. These modifiers had become well established as interpersonal NP adjuncts by the time transparent free relatives cropped up in the late nineteenth century.

\section{Conclusion}

The present study set out to investigate the diachrony of peripheral modifiers, a somewhat neglected type of NP modification. These modifiers, which express interpersonal meanings and occupy a slot in the left-periphery of the NP, have steadily been increasing in frequency since Early Modern English, on both the token level and the type level. The accretion of the peripheral modifier still continues today: both its frequency and its complexity have been rising precipitously from Late Modern English to Present-day English.

The first step in the whole process was a series of semantic changes in a certain class of adverbs. They first became focusing modifiers, and later became integrated in the NP that functioned as its semantic argument by a process of what Harris \& Campbell (1995) have called 'reordering to adjacency'. Next, this relatively inconspicuous Early Modern English slot underwent analogical extension: a whole group of interpersonal adverbs wormed their way into the NP, and since at least a century ago, the slot has become available for clause fragments such as the transparent free relatives. As argued in section 7, the whole development is best accounted for in an onomasiological, constructional and usage-based view of grammaticalisation.

Author's address:

Department of Linguistics/Faculty of Arts

Research Foundation Flanders (FWO)/University of Leuven

Blijde Inkomststraat 21

P.O. Box 3308

3000 Leuven

Belgium

freek.vandevelde@arts.kuleuven.be

\section{Corpora}

BYU-BNC: The British National Corpus. http://corpus.byu.edu/bnc

CB: COBUILD Corpus: Collins Wordbanks Online Service. www.collins.co.uk/cobuild

CEMET: Corpus of Early Modern English Texts

CLMETEV: Corpus of Late Modern English

Oxford English Dictionary. www.oed.com 


\section{References}

Abney, Steven. 1987. The English noun phrase and its sentential aspect. PhD dissertation, MIT. Adamson, Sylvia. 2000. A lovely little example: Word order options and category shift in the premodifying string. In Olga Fischer, Anette Rosenbach \& Dieter Stein (eds.), Pathways of change: Grammaticalization in English, 39-66. Amsterdam: John Benjamins.

Barbiers, Sjef. 1995. The syntax of interpretation. The Hague: Holland Academic Graphics.

Biber, Douglas, Stig Johansson, Geoffrey Leech, Susan Conrad \& Edward Finegan. 1999. Longman grammar of spoken and written English. London: Longman.

Blanche-Benveniste, Claire. 1997. Approches de la langue parlée en français. Gap: Ophrys.

Bouma, Gosse, Petra Hendriks \& Jack Hoeksema. 2007. Focus particles inside prepositional phrases: A comparison of Dutch, English and German. Journal of Comparative Germanic Linguistics 10, 1-4.

Breban, Tine. 2010. English adjectives of comparison: Lexical and grammaticalized uses. Berlin: Mouton de Gruyter.

Brems, Lieselotte. 2007. The synchronic layering of size noun and type noun constructions in English. PhD dissertation, University of Leuven.

Brems, Lieselotte. 2010. Size noun constructions as collocationally constrained constructions: Lexical and grammaticalized uses. English Language and Linguistics 14, 83-109.

Brinton, Laurel. 1996. Pragmatic markers in English: Grammaticalization and discourse functions. Berlin: Mouton de Gruyter.

Brinton, Laurel. 2000. The structure of modern English: A linguistic introduction. Amsterdam: John Benjamins.

Brinton, Laurel. 2008. The comment clause in English: Syntactic origins and pragmatic development. Cambridge: Cambridge University Press.

Bybee, Joan. 2003. Cognitive processes in grammaticalization. In Michael Tomasello (ed.), The new psychology of language, vol. 2: Cognitive and functional approaches to language structure, 145-67. Mahwah, NJ: Lawrence Erlbaum Associates.

Bybee, Joan. 2007. Historical linguistics. In Dirk Geeraerts \& Hubert Cuyckens (eds.), The Oxford handbook of cognitive linguistics, 945-87. Oxford: Oxford University Press.

Croft, William. 2000. Explaining language change: An evolutionary approach. Harlow: Longman.

Croft, William. 2001. Radical Construction Grammar. Oxford: Oxford University Press.

Croft, William. 2010. The origins of grammaticalization in the verbalization of experience. Linguistics 48, 1-48.

Davidse, Kristin. 2004. The interaction of identification and quantification in English determiners. In Michel Achard \& Suzanne Kemmer (eds.), Language, culture and mind, 507-33. Stanford: CSLI Publications.

Davidse, Kristin, Tine Breban \& An Van linden. 2008. The development of secondary deictic meanings by adjectives in the English NP. English Language and Linguistics 12, 475-503.

Denison, David. 2006. Category change and gradience in the determiner system. In Van Kemenade \& Los (eds.), 279-304.

De Smet, Hendrik. 2005. A corpus of Late Modern English. ICAME Journal 29, 69-82.

De Smet, Hendrik. 2009. Analysing reanalysis. Lingua 119, 1728-55.

De Smet, Hendrik \& Jean-Christophe Verstraete. 2006. Coming to terms with subjectivity. Cognitive Linguistics 17, 365-92.

Diessel, Holger. 1999. Demonstratives: Form, function, and grammaticalization. Amsterdam: John Benjamins. 
Diessel, Holger. 2008. Pronominal and adnominal demonstratives. In Martin Haspelmath, Matthew Dryer, David Gil \& Bernard Comrie (eds.), The world atlas of language structures online. Munich: Max Planck Digital Library, chapter 42. http: //wals.info/feature/42.

Dixon, R. M. W. 2003. Demonstratives. A cross-linguistic typology. Studies in Language 27, 61-112.

Dryer, Matthew. 2007. Noun phrase structure. In Timothy Shopen (ed.), Language typology and syntactic description, vol. 2: Complex constructions, 151-205. Cambridge: Cambridge University Press.

Du Bois, John. 1985. Competing motivations. In John Haiman (ed.), Iconicity in syntax, 343-65. Amsterdam: John Benjamins.

Eckhardt, Regine. 2001. Reanalysing selbst. Natural Language Semantics 9, 371-412.

Evans, Nicholas \& David Wilkins. 2000. In the mind's ear: The semantic extensions of perception verbs in Australian languages. Language 76, 546-92.

Evans, Nicholas \& Stephen Levinson. 2009. The myth of language universals: Language diversity and its importance for cognitive science. Behavioral and Brain Sciences 32, 429-92.

Fischer, Olga. 2007. Morphosyntactic change: Functional and formal perspectives. Oxford: Oxford University Press.

Fischer, Olga. 2008. On analogy as the motivation for grammaticalization. Studies in Language 32, 336-82.

Francis, Elaine \& Etsuyo Yuasa. 2008. A multi-modular approach to gradual change in grammaticalization. Journal of Linguistics 44, 45-86.

Givón, Talmy. 1993. English grammar: A function-based introduction. Amsterdam: John Benjamins.

Halliday, Michael. 1994. An introduction to functional grammar, 2nd edn. London: Arnold.

Harbert, Wayne. 2007. The Germanic languages. Cambridge: Cambridge University Press.

Harris, Alice \& Lyle Campbell. 1995. Historical syntax in cross-linguistic perspective. Cambridge: Cambridge University Press.

Hawkins, John A. 2004. Efficiency and complexity in grammars. Oxford: Oxford University Press.

Heine, Bernd. 1997. Possession: Cognitive sources, forces, and grammaticalization. Cambridge: Cambridge University Press.

Heine, Bernd. 2002. On the role of context in grammaticalization. In Ilse Wischer \& Gabriele Diewald (eds.), New reflections on grammaticalization, 83-101. Amsterdam: John Benjamins.

Heine, Bernd. 2003. Grammaticalization. In Joseph \& Janda (eds.), 575-601.

Heine, Bernd \& Tania Kuteva. 2007. The genesis of grammar: A reconstruction. Oxford: Oxford University Press.

Himmelmann, Nikolaus. 1997. Deiktikon, Artikel, Nominalphrase: Zur Emergenz syntaktischer Struktur. Tübingen: Niemeyer.

Hoeksema, Jack. 2002. Polarity-sensitive scalar particles in early modern and present-day Dutch: Distributional differences and diachronic developments. Belgian Journal of Linguistics 16, 53-64.

Hoffmann, Sebastian. 2004. Are low-frequency complex prepositions grammaticalized? On the limits of corpus data - and the importance of intuition. In Lindquist \& Mair (eds.), 171-210.

Huddleston, Rodney. 1988. English grammar: An outline. Cambridge: Cambridge University Press.

Huddleston, Rodney, Geoffrey Pullum \& Peter Peterson. 2002. Relative constructions and unbounded dependencies. In Huddleston \& Pullum et al., 1031-96. 
Huddleston, Rodney \& Geoffrey Pullum et al. 2002. The Cambridge grammar of the English language. Cambridge: Cambridge University Press.

Joseph, Brian \& Richard Janda (eds.). 2003. The handbook of historical linguistics. Oxford: Blackwell.

Lakoff, G. 1974. Syntactic amalgams. Chicago Linguistic Society 10, 321-44.

Lehmann, Christian. 1985. Grammaticalization: Synchronic variation and diachronic change. Lingua e Stile 20, 303-18.

Lindquist, Hans \& Christian Mair (eds.). 2004. Corpus approaches to grammaticalization in English. Amsterdam: John Benjamins.

Lyons, Christopher. 1999. Definiteness. Cambridge: Cambridge University Press.

Mair, Christian. 2004. Corpus linguistics and grammaticalisation theory. Lindquist \& Mair (eds.), 121-50.

Matthews, Peter. 2007. Syntactic relations: A critical survey. Cambridge: Cambridge University Press.

McCawley, James. 1988. The syntactic phenomena of English. Chicago: Chicago University Press.

Nevalainen, Terttu. 1991. But, only, just. Focusing adverbial change in Modern English 1500-1900. Helsinki: Société Néophilologique.

Nevalainen, Terttu. 1994. Aspects of adverbial change in Early Modern English. In Dieter Kastovsky (ed.), Studies in Early Modern English, 243-59. Berlin: Mouton de Gruyter.

Noël, Dirk. 2007. Diachronic construction grammar and grammaticalization theory. Functions of Language 14, 177-202.

Payne, John \& Rodney Huddleston. 2002. Nouns and noun phrases. In Huddleston \& Pullum et al., 423-523.

Payne, John, Rodney Huddleston \& Geoffrey Pullum. 2010. The distribution and category status of adjectives and adverbs. Word Structure 3, 31-81.

Pullum, Geoffrey \& Rodney Huddleston 2002. Adjectives and adverbs. In Huddleston \& Pullum et al., 525-61.

Pustet, Regina. 2004. Zipf and his heirs. Language Sciences 26, 1-25.

Quirk, Randolph, Sidney Greenbaum, Geoffrey Leech \& Jan Svartvik. 1985. A comprehensive grammar of the English language. London: Longman.

Ramat, Paolo \& Davide Ricca. 1998. Sentence adverbs in the languages of Europe. In Johan Van der Auwera (ed.), Adverbial constructions in the languages of Europe, 187-275. Berlin: Mouton de Gruyter.

Roberts, Ian \& Anna Roussou. 2003. Syntactic change: A minimalist approach to grammaticalization. Cambridge: Cambridge University Press.

Robinson, Jane. 1970. Dependency structures and transformational rules. Language 46, 259-85.

Rosenbach, Anette. 2007. Emerging variation: Determiner genitives and noun modifiers in English. English Language and Linguistics 11, 143-89.

Schelfhout, Carla, Peter-Arno Coppen, \& Nelleke Oostdijk. 2004. Transparent free relatives. In Sylvia Blaho, Luis Vicente \& Mark de Vos (eds.), Proceedings of CONSOLE XII. www.sole.leidenuniv.nl/content_docs/ConsoleXII2003pdfs/schelfhout-2003.pdf.

Scott, Gary-John. 2002. Stacked adjectival modification and the structure of nominal phrases. In Guglielmo Cinque (ed.), The cartography of syntactic structures, vol. 1: Functional structure in DP and IP, 91-120. Oxford: Oxford University Press.

Sinclair, John et al. (eds.). 1990. The Collins COBUILD English grammar. London: Collins. Speelman, Dirk. 1997. Abundantia verborum: A corpus-tool for carrying out corpus-based linguistic case studies. $\mathrm{PhD}$ dissertation, University of Leuven. 
Sportiche, Dominique. 1988. A theory of floating quantifiers and its corrolaries for constituent structure. Linguistic Inquiry 19, 425-49.

Swan, Toril. 1988. Sentence adverbials in English: A synchronic and diachronic investigation. Oslo: Novus.

Tabor, Whitney \& Elizabeth Traugott. 1998. Structural scope expansion and grammaticalization. In Anna Giacalone Ramat \& Paul Hopper (eds.), The limits of grammaticalization, 227-70. Amsterdam: John Benjamins.

Thompson, Sandra \& Anthony Mulac. 1991. A quantitative perspective on the gramaticization of epistemic parentheticals in English. In Elizabeth Traugott \& Bernd Heine (eds.), Approaches to grammaticalization, 313-29. Amsterdam: John Benjamins.

Traugott, Elizabeth. 1995. Subjectification in grammaticalisation. In Susan Wright \& Dieter Stein (eds.), Subjectivity and subjectivisation: Linguistic perspectives, 31-54. Cambridge: Cambridge University Press.

Traugott, Elizabeth. 2003. Constructions in grammaticalization. In Joseph \& Janda (eds.), 624-47.

Traugott, Elizabeth. 2006. The semantic development of scalar focus modifiers. In Van Kemenade \& Los (eds.), 335-59.

Traugott, Elizabeth. 2008a. Grammaticalization, constructions and the incremental development of language: Suggestions from the development of degree modifiers in English. In Regine Eckardt, Gerhard Jäger \& Tonjes Veenstra (eds.), Variation, selection, development: Probing the evolutionary model of language change, 219-50. Berlin: Mouton de Gruyter.

Traugott, Elizabeth. 2008b. The grammaticalization of NP of NP constructions. In Alexander Bergs \& Gabriele Diewald (eds.), Constructions and language change, 21-43. Berlin: Mouton de Gruyter.

Trousdale, Graeme. 2008. Words and constructions in grammaticalization: The end of the English impersonal construction. In Susan Fitzmaurice \& Donka Minkova (eds.), Studies in the history of the English language, vol. IV: Empirical and analytical advances in the study of English language change, 301-26. Berlin: Mouton de Gruyter.

Tucker, Gordon. 1998. The lexicogrammar of adjectives: A systemic functional approach to lexis. London: Cassell.

Van Bogaert, Julie. 2010. A constructional taxonomy of I think and related expressions: Accounting for the variability of complement-taking mental predicates. English Language and Linguistics 14, 399-427.

Van de Velde, Freek. 2009a. Do we need the category of postdeterminer in the NP? Transactions of the Philological Society 107, 293-321.

Van de Velde, Freek. 2009b. De nominale constituent: Structuur en geschiedenis. Leuven: Leuven University Press.

Van de Velde, Freek. 2009c. The emergence of modification patterns in the Dutch noun phrase. Linguistics 47, 1021-49.

Van Kemenade, Ans \& Bettelou Los (eds.). 2006. The handbook of the history of English. Oxford: Blackwell.

Van Riemsdijk, Henk. 2000. Free relatives inside out: Transparent free relatives as grafts. In Bożena Rozwadowska (ed.), Proceedings of the 1999 PASE Conference, 223-33. Wrocław: University of Wrocław.

Van Riemsdijk, Henk. 2001. A far from simple matter: Syntactic reflexes of syntax-pragmatics misalignments. In István Kenesei \& Robert Harnish (eds.), Perspectives on semantics, pragmatics and discourse: A Festschrift for Ferenc Kiefer, 21-41. Amsterdam: John Benjamins.

Vincent, Nigel. 1999. The evolution of c-structure: prepositions and PPs from Indo-European to Romance. Linguistics 37, 1111-53. 
Wilder, Chris. 1999. Transparent free relatives. In N. Shahin Kimary, Susan Blake \& Kim Eun-Sook (eds.), Proceedings of the Seventeenth West Coast Conference on Formal Linguistics, 685-99. Cambridge: Cambridge University Press.

Wustmann, Gustav. 1896. Allerhand Sprachdummheiten: Kleine deutsche Grammatik des Zweifelhaften, des Falschen und des Häßlichen. Ein Hilfsbuch für all die sich öffentlich der deutsche Sprache bedienen, 2nd edn. Leipzig: Grunow.

Zaalberg, Carlo. 1975. Taaltrouw. Nieuwe en oude glottagogische overwegingen. Culemborg: Willink/Noorduijn.

Zwicky, Arnold. 1978. Arguing for constituents. Chicago Linguistic Society 14, 503-12. 